\title{
Dexamethasone-Induced Ocular Hypertension in Mice
}

\section{Effects of Myocilin and Route of Administration}

Gaurang C. Patel, Tien N. Phan, Prabhavathi Maddineni, Ramesh B. Kasetti, J. Cameron Millar, Abbot F. Clark, and Gulab S. Zode

From the North Texas Eye Research Institute, University of North Texas Health Science Center, Fort Worth, Texas

\author{
Accepted for publication \\ December 8, 2016. \\ Address correspondence to \\ Gulab S. Zode, Ph.D., or Abbot \\ F. Clark, Ph.D., North Texas Eye \\ Research Institute, University of \\ North Texas Health Science \\ Center, 3500 Camp Bowie Blvd, \\ Fort Worth, TX 76107. E-mail: \\ gulab.zode@unthsc.edu or abe. \\ clark@unthsc.edu.
}

\begin{abstract}
Glucocorticoid (GC)-induced ocular hypertension (OHT) is a serious adverse effect of prolonged GC therapy that can lead to iatrogenic glaucoma and permanent vision loss. An appropriate mouse model can help us understand precise molecular mechanisms and etiology of GC-induced OHT. We therefore developed a novel, simple, and reproducible mouse model of GC-induced $\mathrm{OHT}$. GC-induced myocilin expression in the trabecular meshwork (TM) has been suggested to play an important role in GC-induced $\mathrm{OHT}$. We further determined whether myocilin contributes to $\mathrm{GC}-\mathrm{OHT}$. C57BL/6J mice received weekly periocular conjunctival fornix injections of a dexamethasone-21-acetate (DEX-AC) formulation. Intraocular pressure (IOP) elevation was relatively rapid and significant, and correlated with reduced conventional outflow facility. Nighttime IOPs were higher in ocular hypertensive eyes compared to daytime IOPs. DEX-Ac treatment led to increased expression of fibronectin, collagen I, and $\alpha$-smooth muscle actin in the TM in mouse eyes. No changes in body weight indicated no systemic toxicity associated with DEX-Ac treatment. Wild-type mice showed increased myocilin expression in the TM on DEX-Ac treatment. Both wild-type and $\mathrm{MyOC}^{-/-}$mice had equivalent and significantly elevated IOP with DEX-Ac treatment every week. In conclusion, our mouse model mimics many aspects of GC-induced OHT in humans, and we further demonstrate that myocilin does not play a major role in DEX-induced OHT in mice. (Am J Pathol 2017, 187: 713-723; http://dx.doi.org/10.1016/j.ajpath.2016.12.003)
\end{abstract}

Glucocorticoids (GCs) are one of the most commonly prescribed medications worldwide for the treatment of a plethora of diseases and conditions. Because of their broadspectrum anti-inflammatory and immunosuppressive properties, the worldwide market for GC use is estimated to be $>\$ 10$ billion per year. ${ }^{1}$ Approximately $1.2 \%$ of US and $0.85 \%$ of UK populations are prescribed therapeutic GCs every year. ${ }^{2,3}$ GCs also remain the mainstay of treatment for a variety of ocular inflammatory diseases involving almost all tissues of the eye, such as eyelids, conjunctiva, cornea, sclera, uvea, retina, and optic nerve. ${ }^{4}$ The routes of GC administration in treatment of these disorders can be topical ocular, oral, systemic, intravitreal injections and implants, and periocular injections (including subconjunctival, subtenon, retrobulbar, and peribulbar). ${ }^{5}$ However, prolonged GC therapy is associated with serious ocular adverse effects, including development of posterior subcapsular cataracts, and the development of GC-induced ocular hypertension (GC-OHT) and iatrogenic open-angle glaucoma.

The clinical presentation of GC-induced glaucoma is similar to primary open-angle glaucoma (POAG), and for $>50$ years, reports have suggested a link between glaucoma and GCs. Development of GC-induced OHT depends on GC dose and duration of treatment, method of administration, potency of $\mathrm{GC}$, and individual susceptibility to GCs. ${ }^{6-8}$ There are varying degrees of steroid responsiveness (ie, development of GC-OHT) among individuals; $90 \%$ of glaucoma patients are steroid responders compared to $40 \%$ of the general population..$^{6-10}$ If left untreated, GC-induced OHT progresses to secondary open-angle

Supported by National Eye Institute grants R01EY016242 (A.F.C.), EY022077 (G.S.Z.), and EY026177 (G.S.Z.).

Disclosures: None declared. 
glaucoma, with the development of glaucomatous optic neuropathy and permanent vision loss.

Similar to POAG, GC-induced OHT is also caused by increased aqueous humor outflow resistance and is associated with similar biochemical and morphological changes in the trabecular meshwork (TM) of the outflow pathway. ${ }^{4-8}$ The TM is a small filter-like tissue consisting of TM cells with a sieve-like extracellular matrix that maintains normal intraocular pressure (IOP) by regulating aqueous humor outflow resistance. GCs cause physical and mechanical changes in the microstructure of the TM, leading to elevated IOP. GCs alter TM cellular functions, including increased TM cell and nucleus sizes, inhibition of cell proliferation and migration, and altered cellular junctional complexes. ${ }^{11,12}$ GCs reorganize the TM cell actin cytoskeleton by forming cross-linked actin networks, ${ }^{13-16}$ which are geodesic dome-like structures and/or tangles of actin filaments. These morphological and biochemical changes alter TM stiffness and impair TM functions, such as phagocytosis, ${ }^{17}$ adversely affecting the aqueous outflow pathway. GCs also cause excessive deposition of extracellular matrix material in the TM with induction of glycosaminoglycans, ${ }^{18,19}$ fibronectin, ${ }^{20}$ laminin, ${ }^{21}$ collagens, ${ }^{22}$ and elastin. ${ }^{23}$

Several laboratories have attempted to identify genes/ proteins involved in the development of GC-OHT in TM cells in response to GCs. In the late 1980s, Polansky and colleagues $^{23}$ identified a 57-kDa glycoprotein that was induced by dexamethasone (DEX) in primary TM cell cultures. This gene and protein initially was called trabecular meshwork inducible glucocorticoid response. ${ }^{23,24}$ Concurrently, genetic linkage studies mapped and subsequently identified trabecular meshwork inducible glucocorticoid response as the first glaucoma gene responsible for $4 \%$ of POAG cases. $^{25-27}$ This trabecular meshwork inducible glucocorticoid response gene was later identified as myocilin (MYOC). ${ }^{28}$ Approximately 3\% to 5\% of POAG patients have mutations in MYOC. ${ }^{29,30}$ The exact role of wild-type (WT) MYOC is not completely understood. Various genetic strategies, including knockout, knock-in, or transient expression of transgenic mutant $M Y O C$, were tested in mouse models. ${ }^{31-38}$ Because GC treatment induces MYOC expression in TM cells, it was hypothesized that increased myocilin accumulation in the TM leads to blockage of aqueous humor flow, causing increased IOP and steroid-induced glaucoma. However, when this hypothesis was tested in transgenic Myoc mice, which overexpressed WT myocilin 15-fold compared to normal mice, these transgenic mice did not exhibit glaucoma, indicating that overexpression of WT myocilin alone does not cause glaucoma in mice. ${ }^{31}$ Furthermore, myocilin knockout mice did not show glaucoma phenotypes, suggesting that myocilin is not required for regulation of IOP. Several studies have demonstrated that glaucomatous mutations in MYOC cause gain of function in which misfolded myocilin accumulates intracellularly, ${ }^{39}$ inducing endoplasmic reticulum stress-mediated TM cell death and IOP elevation. ${ }^{38,40-42}$
However, it is unclear whether WT myocilin plays any role in GC-induced OHT because of lack of an appropriate mouse model of GC-induced OHT. Recently, several laboratories have demonstrated DEX-induced ocular hypertension in mice. Both systemic and topical delivery of DEX has been shown to induce OHT in mice. ${ }^{40,43}$ Kumar et $\mathrm{al}^{44}$ used subconjunctival delivery of triamcinolone acetonide in attempt to induce GC-OHT. However, these models have their benefits as well as drawbacks. Systemic delivery of DEX using implanted minipumps elevated IOP by 3 to $4 \mathrm{mmHg}$ at 3 to 4 weeks, which correlated with reduction in outflow facility. However, minipump delivery of DEX has significant limitations, including requiring invasive surgery for implantation, elevated blood pressure, lymphopenia, and a high dropout rate of mice associated with reduction in body weight because of systemic DEX treatment. ${ }^{43,45}$ Topical DEX $(0.1 \%)$ elevated the IOP by 7 to $8 \mathrm{mmHg}$ at 6 weeks and was associated with loss of retinal ganglion cells and optic nerve axons, but this method requires administering eye drops three times daily for multiple weeks by a trained technician. ${ }^{40}$ The subconjunctival triamcinolone acetonide injection reduced the aqueous outflow facility but was not able to significantly elevate IOP. ${ }^{44}$

There is a significant need for an easy and reproducible mouse model of GC-OHT. In humans, slow-release GC formulations or devices in the eye lead to sustained IOP elevations in susceptible individuals. Therefore, we hypothesized that slow-release deposits of the less soluble DEX-21-acetate (DEX-Ac) may reduce dosing frequency and exhibit sustained IOP elevation. We tested several different formulations and injection techniques to identify an effective and consistent model of GC-OHT. In addition to developing a new reproducible mouse model of GC-OHT using periocular conjunctival fornix (CF) injections of DEX-Ac, another goal of our study was to determine the potential effects of myocilin on GC-induced OHT.

\section{Materials and Methods}

\section{Animals}

Male and female C57BL/6J and myocilin knockout $\left(\mathrm{Myoc}^{-{ }^{--}}\right)$ mice on a pure $\mathrm{C} 57 \mathrm{BL} / 6 \mathrm{~J}$ background were obtained from the Jackson Laboratory (Bar Harbor, ME). All mice were 6 to 8 months old at the start of experiments. All mouse studies and care were performed in compliance with the Association for Research in Vision and Ophthalmology Statement of the Use of Animals in Ophthalmic and Vision Research and the University of North Texas Health Science Center Institutional Animal Care and Use Committee regulations. Mice were housed under controlled conditions of temperature $\left(21^{\circ} \mathrm{C}\right.$ to $26^{\circ} \mathrm{C}$ ), humidity ( $40 \%$ to $70 \%$ ), and a 12 -hour light/12-hour dark cycle. Food and water were provided ad libitum. The number of animals used in each experiment is indicated in the corresponding figure legends and Results. 
Table 1 Preparation of Injection Vehicle Suspension Formulation

\begin{tabular}{ll}
\hline Injection vehicle suspension formulation & \\
\hline Contents & Volume $/ 100 \mathrm{~mL}$ \\
\hline Sodium chloride USP granular & $0.667 \mathrm{~g}$ \\
Creatinine NF & $0.5 \mathrm{~g}$ \\
Edetate disodium USP dihydrate & $0.05 \mathrm{~g}$ \\
Carboxymethylcellulose sodium USP (medium & $0.5 \mathrm{~g}$ \\
$\quad$ viscosity) & \\
Polysorbate 80 NF & $0.1 \mathrm{~mL}$ \\
Benzyl alcohol NF & $0.9 \mathrm{~g}$ \\
Sodium bisulfite FCC & $0.1 \mathrm{~g}$ \\
Sodium hydroxide 1\% & Adjust pH to 7 \\
Water for injection, USP & $100 \mathrm{~mL}$ \\
\hline
\end{tabular}

FCC, Food Chemicals Codex; NF, National Formulary; USP, United States Pharmacopeia.

\section{DEX Formulations}

\section{Vehicle for Suspension Formulations}

Our injection vehicle for suspension formulation was prepared as described in Table 1. Each ingredient was added sequentially and mixed in $70 \mathrm{~mL}$ of water for injection, adjusted to $\mathrm{pH} 7$, and then brought to final volume with water for injection. This formulation was transferred into 10 -mL amber glass bottles and sealed. The preparation was autoclaved at $121^{\circ} \mathrm{C}, 15 \mathrm{psi}$, for 20 minutes. After that, the vehicle was allowed to cool and kept at $4^{\circ} \mathrm{C}$ until further use. The preparation is stable for 90 days.

\section{DEX-Ac Formulation}

For preparation of $10 \mathrm{mg} / \mathrm{mL}$ of DEX-Ac suspension, $0.01 \mathrm{~g}$ of DEX-Ac, anhydrous micronized powder (Spectrum Chemicals, New Brunswick, NJ) was mixed with $1 \mathrm{~mL}$ of vehicle suspension in a sterile $2-\mathrm{mL}$ microcentrifuge tube. This suspension was mixed using two stainless steel 5-mm beads (Qiagen, Valencia, CA) in a TissueLyser LT (Qiagen) for 5 minutes at 50 oscillations per second. This disrupts and homogenizes the DEX-Ac particles to ensure a fine drug particle size for the formulation. After this step, the microcentrifuge with drug was wrapped with aluminum foil to protect from light and rotated overnight at $4^{\circ} \mathrm{C}$ or until further use. The DEX-Ac formulations were prepared fresh every 2 weeks. This DEX-Ac suspension can form larger particles (clumps) after 2 weeks. These larger DEX-Ac particles or clumps can clog the syringe needle and cause variable amounts of drug delivered with each injection.

\section{Additional DEX Formulations}

We initially tried two formulations for preparing $10 \mathrm{mg} / \mathrm{mL}$ DEX. DEX powder (0.01 g; catalog number D4902; Sigma, St. Louis, MO) was mixed with $1 \mathrm{~mL}$ of vehicle suspension or sesame oil in a sterile 2-mL microcentrifuge tube. Similar procedures were followed, as described above, to get the DEX formulation.
Dexamethasone sodium phosphate injection solution $(10 \mathrm{mg} / \mathrm{mL}$ ) was obtained from a commercial source (WestWard Pharmaceuticals Corp., Eatontown, NJ).

\section{Routes of DEX Administration}

Before and during injections, mice were anesthetized with isoflurane $(2.5 \%)$ and oxygen $(0.8 \mathrm{~L} /$ minute). For topical anesthesia, both eyes received one to two drops of $0.5 \%$ proparacaine $\mathrm{HCl}$ (Akorn Inc., Lake Forest, IL).

\section{Periocular CF Injection}

For periocular injection, a 32-gauge needle with a Hamilton glass microsyringe $(25-\mu \mathrm{L}$ volume; Hamilton Company, Reno, NV) was used. The lower eyelid was retracted, and the needle was inserted through the CF. DEX-Ac or vehicle suspension $(20 \mu \mathrm{L})$ was injected immediately under the CF over the course of 10 to 15 seconds. The needle was then withdrawn. The procedure was performed on both eyes of each animal (each animal receiving either DEX-Ac in both eyes or vehicle in both eyes). Mice were treated with DEXAc or vehicle once per week until the end of the study.

\section{Subconjunctival Injection}

For subconjunctival injection, a 32-gauge needle with a glass microsyringe (25- $\mu \mathrm{L}$ volume; Hamilton Company) was used. The lower eyelid was retracted, and the conjunctiva was gently pulled away from the surface of the globe using forceps. DEX, DEX-Ac, or vehicle suspension $(20 \mu \mathrm{L})$ was injected immediately under the conjunctiva over the course of 20 to 25 seconds. The needle was then withdrawn. The procedure was performed on both eyes of each animal (each animal receiving a subconjunctival injection of either DEX in both eyes or vehicle in both eyes).

\section{Intravitreal Injection}

For intravitreal injection, a 33-gauge needle with a glass microsyringe $(10-\mu \mathrm{L}$ volume; Hamilton Company) was used. The eye was proptosed, and the needle was inserted through the equatorial sclera and inserted into the vitreous chamber at an angle of approximately 45 degrees, taking care to avoid touching the posterior part of the lens or the retina. DEX or vehicle suspension $(3 \mu \mathrm{L})$ was injected into the vitreous over the course of 1 minute. The needle was then left in place for a further 30 seconds (to facilitate mixing), before being rapidly withdrawn.

\section{IOP Measurements}

For this study, both conscious and anesthetized IOPs were measured during day and night, respectively. During daytime, conscious IOPs were measured in behaviorally trained mice using a TonoLab rebound tonometer (Colonial Medical Supply, Franconia, NH) every week, following our previously published method. ${ }^{46}$ All daytime IOP measurements were performed in both eyes between $10 \mathrm{AM}$ and 2 PM. 
IOPs were measured before the weekly injections. For nighttime IOP measurement, mice were first kept in dark at 4 PM on day of IOP measurement, and at $10 \mathrm{PM}$, anesthetized IOPs were measured in both eyes using TonoLab rebound tonometer twice a week. The entire procedure was performed under red light in a darkroom. Two separate laboratories performed injections and IOP measurements independently (Zode laboratory, conscious daytime IOPs; and Clark laboratory, nighttime IOPs) in a masked manner. IOP data from each laboratory are reported as two independent experiments, and the results reported have been replicated numerous times.

\section{Aqueous Humor Outflow Facility Measurements}

Measurements were recorded in live mice, as previously described. ${ }^{47,48}$ Mice were anesthetized using a 100/10 mg/kg ketamine/xylazine cocktail. A quarter to half of this dose was administered for maintenance of anesthesia as necessary. After attainment of a surgical plane of anesthesia, animals were placed on a heated pad $\left(37^{\circ} \mathrm{C}\right)$ for maintenance of body temperature. One to two drops of proparacaine $\mathrm{HCl}(0.5 \%$; Akorn Inc.) were applied topically to both eyes for corneal anesthesia. The anterior chambers of both eyes were cannulated using a 30-gauge needle inserted through the cornea 1 to $2 \mathrm{~mm}$ from the limbus and pushed across the chamber to a point in the chamber angle opposite to the point of cannulation, taking care not to touch the iris, anterior lens capsule or epithelium, or corneal endothelium. Each cannulating needle was connected to a previously calibrated (sphygmomanometer; Diagnostix 700, Hauppage, NY) flow-through BLPR-2 pressure transducer [World Precision Instruments (WPI), Sarasota, FL] for continuous determination of pressure within the perfusion system. A drop of phosphate-buffered saline (PBS) was also administered to each eye to prevent corneal drying. The opposing terminal of the pressure transducer was connected via further tubing to a $1 \mathrm{~mL}$ syringe loaded into a microdialysis infusion pump (SP101I Syringe Pump; WPI). The tubing, transducer, and syringe were all filled with sterile PBS solution (filtered through a $0.2-\mu \mathrm{m}$ HT Tuffryn Membrane Acrodisc Syringe Filter; PALL Gelman Laboratory, Port Washington, NY). Signals from each pressure transducer were passed via a TBM4M Bridge Amplifier (WPI) and a Lab-Trax Analog-to-Digital Converter (WPI) to a computer for display on a virtual chart recorder (LabScribe2 software; WPI). Eyes were initially infused at a flow rate of $0.1 \mu \mathrm{L} /$ minute. When pressures stabilized within 10 to 30 minutes, pressure measurements were recorded over a 10-minute period, and then flow rates were increased sequentially to $0.2,0.3,0.4$, and $0.5 \mu \mathrm{L} /$ minute. Three stabilized pressures at 5-minute intervals at each flow rate were recorded. Aqueous humor outflow facility in each eye of each animal was calculated as the reciprocal of the slope of a plot of mean stabilized pressure as ordinate against flow rate as abscissa.

\section{Histology and Immunofluorescence}

Eyes from DEX-Ac and vehicle-treated mice were enucleated and fixed overnight in freshly prepared $4 \%$ paraformaldehyde in PBS. Afterward, eyes were washed three times with PBS, dehydrated with ethanol, and embedded in paraffin. Samples were divided into sections (5 $\mu \mathrm{m}$ thick) and stained with hematoxylin and eosin for general evaluation of the anterior segment, including structural organization of TM. For immunostaining, tissue sections were deparaffinized in xylene and rehydrated twice each with $100 \%, 95 \%, 70 \%$, and $50 \%$ ethanol for 5 minutes. For antigen retrieval, the tissue sections were incubated in citrate buffer $(\mathrm{pH} 6.0)$ at $100^{\circ} \mathrm{C}$ for 13 minutes and then at room temperature for another 13 minutes. Tissue sections were blocked $(10 \%$ goat serum $+0.2 \%$ Triton-X 100) for 2 hours in a dark and humid chamber. Tissue sections were then washed briefly with PBS and immunolabeled with either rabbit polyclonal fibronectin antibody (1:200; catalog number ab2413; Abcam, Cambridge, MA), rabbit polyclonal collagen I antibody (1:200; catalog number NB600-408; Novus Biologicals, Littleton, $\mathrm{CO}$ ), rabbit polyclonal $\alpha$-smooth muscle actin antibody (1:100; catalog number ab5694; Abcam), or goat polyclonal myocilin (N-15) antibody (1:100; catalog number sc-21243; Santa Cruz Biotechnology, Dallas, TX) and incubated overnight at $4^{\circ} \mathrm{C}$. Tissue sections incubated without primary antibody served as a negative control. After the incubation, tissue sections were washed three times with PBS and further incubated for 2 hours at room temperature with the appropriate secondary antibodies (1:500; Alexa goat anti-rabbit 568 or Alexa donkey anti-goat; Thermo Fisher Scientific, Inc., Waltham, MA). Tissue sections were washed with PBS and mounted with mounting medium containing DAPI nuclear stain (Vector Labs, Inc., Burlingame, CA). Images were captured by Keyence all-in-one fluorescence microscope (Itasca, IL). All antibodies used in this study were validated and characterized previously. ${ }^{49}$

\section{Western Blot Analysis}

Mouse anterior segments were carefully dissected from enucleated eyes and lysed in lysis buffer. The protein samples were run on denaturing $4 \%$ to $12 \%$ gradient polyacrylamide ready-made gels (NuPAGE Bis-Tris gels; Life Technologies, Carlsbad, CA) and transferred onto a polyvinylidene difluoride membrane. Blots were blocked with $10 \%$ nonfat dried milk for 1 hour and then incubated overnight with specific primary antibody at $4{ }^{\circ} \mathrm{C}$ on a rotating shaker. The membranes were washed three times with $1 \times$ PBS with Tween 20 and incubated with corresponding horseradish peroxidase-conjugated secondary antibody for 1.5 hours. The proteins were then visualized using enhanced chemiluminescence detection reagents (SuperSignal West Femto Maximum Sensitivity Substrate; Pierce Biotechnology, Rockford, IL). The antibodies used were as follows: fibronectin antibody (1:1000; catalog number ab2413; Abcam), 
Table 2 Summary of Routes of Delivery and Different Formulations of Dexamethasone

\begin{tabular}{|c|c|c|c|}
\hline \multirow[b]{2}{*}{$\begin{array}{l}\text { Administration } \\
\text { route }\end{array}$} & \multicolumn{3}{|l|}{ Formulation } \\
\hline & Dexamethasone & $\begin{array}{l}\text { Dexamethasone } \\
\text { sodium } \\
\text { phosphate }\end{array}$ & $\begin{array}{l}\text { Dexamethasone } \\
\text { acetate }\end{array}$ \\
\hline Subconjunctival & $\mathrm{NE}$ & NE & NR \\
\hline Intravitreal & $\mathrm{NE}$ & NE & NE \\
\hline Periocular CF & NA & NR & $\mathrm{R}$ \\
\hline
\end{tabular}

$C F$, conjunctival fornix; NA, not available; $N E$, no effect on intraocular pressure; $N R$, not reproducible; $R$, reproducible.

goat polyclonal myocilin (N-15) antibody (1:250; catalog number sc-21243; Santa Cruz Biotechnology), and glyceraldehyde-3-phosphate dehydrogenase $(1: 1000$; catalog number 3683; Cell Signaling Technology, Danvers, MA).

\section{Statistical Analysis}

Statistical analyses were performed using GraphPad Prism version 7.0 (GraphPad Software, La Jolla, CA). An unpaired $t$-test (two tailed) was used to compare data between two groups. Multiple groups were compared using two-way analysis of variance, followed by Bonferroni post hoc test. Statistical significance was determined at $P<0.05$.

\section{Results}

Different dexamethasone drug formulations and routes of administration were tried to develop the GC-OHT mouse model (Table 2 and Supplemental Tables S1-S4) to find an easy, efficient, and reproducible method of GC delivery to eyes to develop GC-OHT. Only the periocular CF injection of DEXAc was reproducible and led to significant and sustained IOP elevations that correlated with reduced outflow facility.

\section{Weekly Periocular CF DEX-Ac Injections Caused Significant and Sustained IOP Elevation in Mice}

Weekly periocular CF injections of DEX-Ac suspension to both eyes of mice caused DEX-induced OHT with sustained and significantly elevated IOP. The periocular $\mathrm{CF}$ site for injection of DEX-Ac and vehicle is shown in Figure 1A.

\section{Conscious Daytime IOP}

Periocular CF injections of DEX-Ac elevated IOP within 1 week of treatment compared to vehicle-treated mice, and IOP elevation was sustained throughout 4 weeks. Treatment of mice with vehicle did not elevate IOP. Conscious mouse IOP differences between DEX-Ac and vehicle groups were sustained to approximately $4 \mathrm{mmHg}(P=0.001)$ starting from the second week of treatment (Figure 1B). The absolute increase in IOP in DEX-Ac $(n=14)$ versus vehicle $(n=10)$ treated mice averaged $2.67 \pm 0.06 \mathrm{mmHg}$ at 1 week, $4.12 \pm 0.03 \mathrm{mmHg}$ at 2 weeks, $3.80 \pm 0.21 \mathrm{mmHg}$ at 3 weeks, and $3.95 \pm 0.30 \mathrm{mmHg}$ at 4 weeks (means $\pm \mathrm{SEM} ; P<0.001$ ).

\section{Anesthetized Nighttime IOP}

IOP elevation was rapid and significantly higher at night in DEX-Ac-treated mice compared with vehicle-treated mice starting from 3 days after injection. IOP differences between vehicle and DEX-Ac-treated mice were significantly higher throughout the study $(P<0.001)$ (Figure $1 C)$. The absolute increases in IOP in DEX-Ac $(n=20)$ versus vehicle $(n=12)$ treated mice averaged $3.0 \pm 0.3 \mathrm{mmHg}$ at day 7 , $7.58 \pm 0.5 \mathrm{mmHg}$ at day $14,8.32 \pm 0.5 \mathrm{mmHg}$ at day 25 , and $9.43 \pm 0.6 \mathrm{mmHg}$ at day 36 (means \pm SEM).
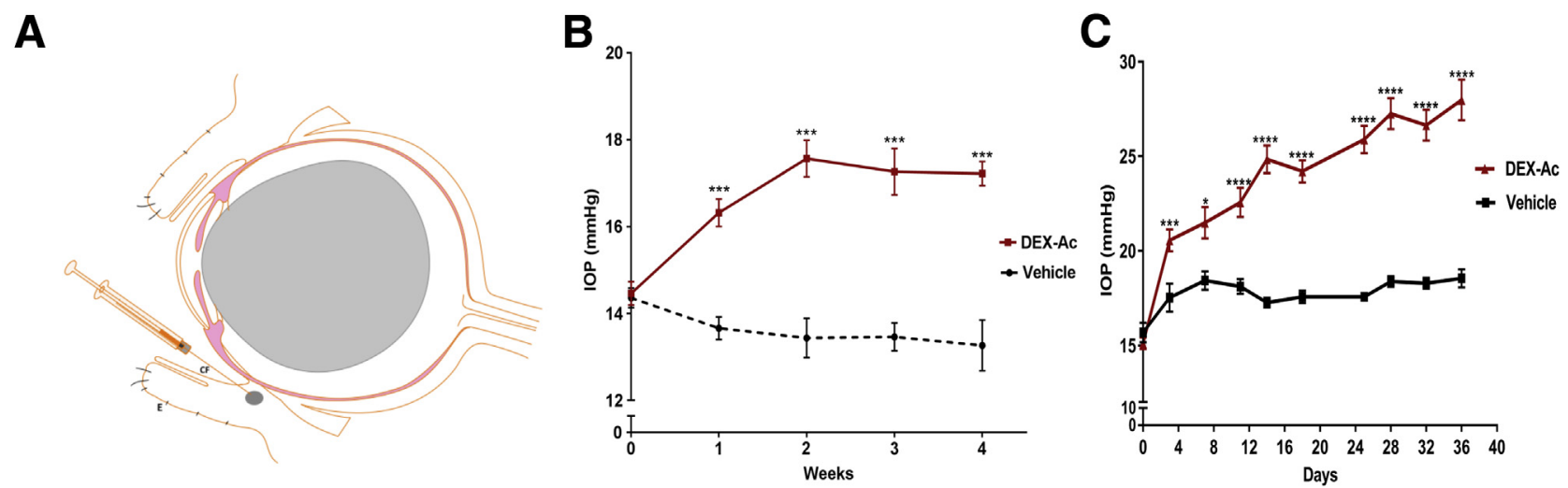

Figure 1 Development of DEX-Ac-induced ocular hypertension in mice. A: Placement of the periocular conjunctival fornix (CF) injection. The lower eyelid (E) is digitally retracted, and a 32-gauge needle is inserted through the CF. DEX-Ac or vehicle suspension $(20 \mu \mathrm{L})$ is injected immediately under the CF over the course of 10 to 15 seconds. The needle is then withdrawn. Weekly periocular injection of DEX-Ac in both eyes significantly elevates intraocular pressure (IOP) in mice. B: Conscious daytime IOP measurements of DEX-Ac - versus vehicle-treated mice show significant IOP elevation starting from 1 week of treatment. C: Nighttime IOP measurements of DEX-Ac- versus vehicle-treated mice show significant IOP elevation from 3 to 36 days. Data are presented as means \pm SEM. $n=10$ (B, DEX-Ac-treated mice); $n=14$ (B, vehicle-treated mice); $n=20$ (C, DEX-Ac-treated mice); $n=12$ (C, vehicle-treated mice). ${ }^{\star} P<0.05$, $* * * P<0.001$, and $* * * * P<0.0001$, unpaired $t$-test. 
After 4 weeks, DEX-Ac treatment was stopped at 4 weeks and IOP was followed, we observed that at 7 weeks, IOP decreased and started returning to its baseline IOP (Supplemental Figure S1). This corresponds to changes observed in human GC-OHT eyes; IOP starts to return to normal levels after cessation of GC therapy.

Although we routinely used mice aged 6 to 8 months, we also tested younger mice (aged 2 to 3 months) and obtained similar results.

\section{Periocular CF Injection of DEX-Ac Reduced Conventional Outflow Facility}

Conventional outflow facility was measured in live mice after 5 weeks of DEX-Ac treatment. Conventional outflow facility was significantly reduced in DEX-Ac mice compared to vehicle-treated mice (Figure 2). Conventional outflow facility was $15.69 \pm 1.36 \mathrm{~nL} / \mathrm{minute} / \mathrm{mmHg}$ in DEX-Ac-treated mice $(n=13)$ compared $23.50 \pm$ $2.09 \mathrm{~nL} / \mathrm{minute} / \mathrm{mmHg}$ in vehicle-treated mice $(P=0.004$; $n=12$ ). This represented a $33 \%$ reduction in conventional outflow facility in DEX-treated mice compared to vehicletreated mice. The mean decrease in outflow facility corresponded well with the mean IOP elevation in DEX-treated mice, according to the modified Goldman equation.

\section{Effect of DEX-Ac Treatment on Body Weight}

Systemic administration of DEX has been shown to decrease the weight in mice. ${ }^{43,45}$ Because it is possible that periocular injections of DEX-Ac have systemic effects, including reduced body weight, we determined whether ocular delivery of DEX-Ac using periocular CF injections in our mouse

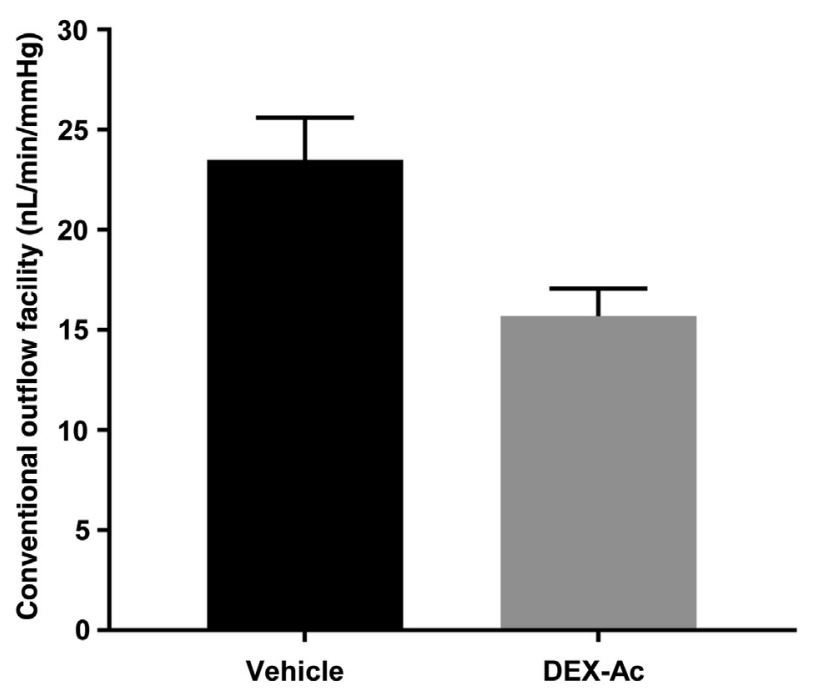

Figure 2 Comparison of conventional outflow facility between DEX-Acand vehicle-treated mice. After 5 weeks of DEX-Ac treatment, conventional outflow facility was significantly reduced in DEX-Ac-treated mice compared to vehicle-treated mice. Data are presented as means \pm SEM. $n=13$ (DEX-Ac-treated mice); $n=12$ (vehicle-treated mice). $P=0.004$, unpaired $t$-test.

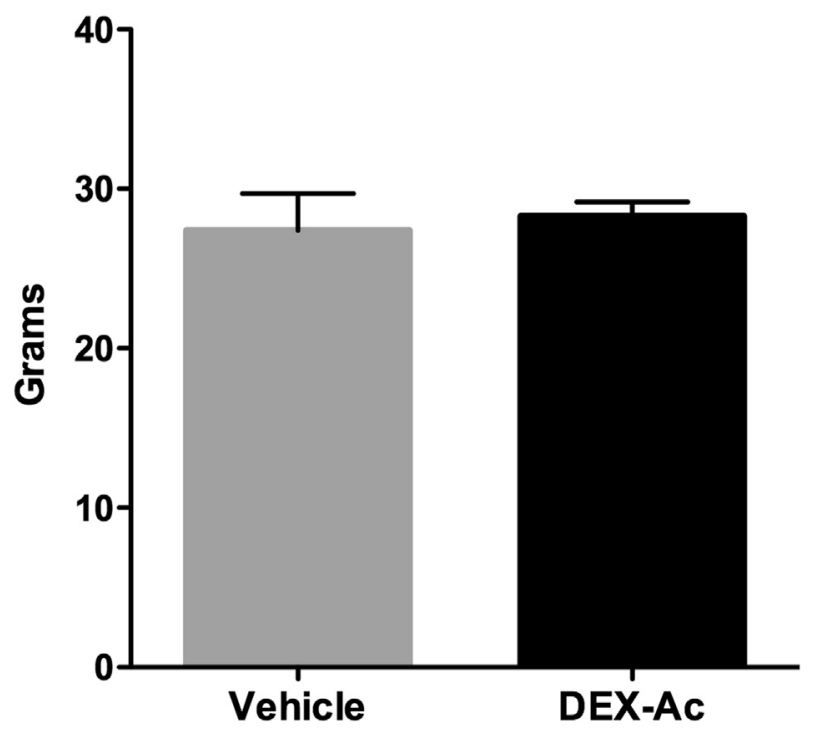

Figure 3 Comparison of body weights between DEX-Ac- and vehicletreated mice. After 4 weeks of weekly DEX-Ac treatment, body weight remained unchanged in DEX-Ac-treated mice compared to vehicle-treated mice. Unpaired $t$-test. Data are presented as means \pm SEM. $n=7$ (DEX-Ac-treated mice); $n=5$ (vehicle-treated mice).

model reduces body weight (Figure 3). Body weights were measured every week over the course of treatment. At the end of 4 weeks, body weight was $28.29 \pm 0.89 \mathrm{~g}$ in DEXAc-treated mice $(n=7)$ compared to $27.40 \pm 2.29 \mathrm{~g}$ in vehicle-treated mice $(n=5)$. DEX-Ac did not alter body weight of mice even after 4 weeks of treatment, suggesting a minimum systemic effect after local DEX-Ac delivery.

\section{Histological Changes in the TM after DEX-Ac Treatment}

DEX treatment leads to many biochemical changes in the $\mathrm{TM}$, including increased production of fibronectin, ${ }^{20}$ collagens, ${ }^{22}$ and actin. ${ }^{13}$ To assess whether treatment with DEX-Ac will also induce these biochemical changes in our model, we performed immunohistochemical analysis for fibronectin, collagen I, and $\alpha$-smooth muscle actin in anterior segment tissues from 4-week DEX-Ac- and vehicletreated mice (Figure 4A). Immunohistochemical analysis revealed increased fibronectin (DEX-Ac, $n=4$; vehicle, $n=4$ ), collagen I (DEX-Ac, $n=5$; vehicle, $n=5$ ), and $\alpha$-smooth muscle actin (DEX-Ac, $n=4$; vehicle, $n=4$ ) expression in the TM of DEX-Ac-treated mice compared to vehicle-treated mice. In addition, hematoxylin and eosin staining revealed no apparent ocular abnormalities and similar TM structural organization in DEX-Ac- and vehicle-treated mice (Figure 4B).

\section{Effect of Myocilin on IOP after DEX-Ac Treatment}

Although GCs induce myocilin protein production in the $\mathrm{TM},{ }^{26}$ its role in regulating IOP and GC-OHT has not been convincingly demonstrated. We first examined whether 


\section{A}
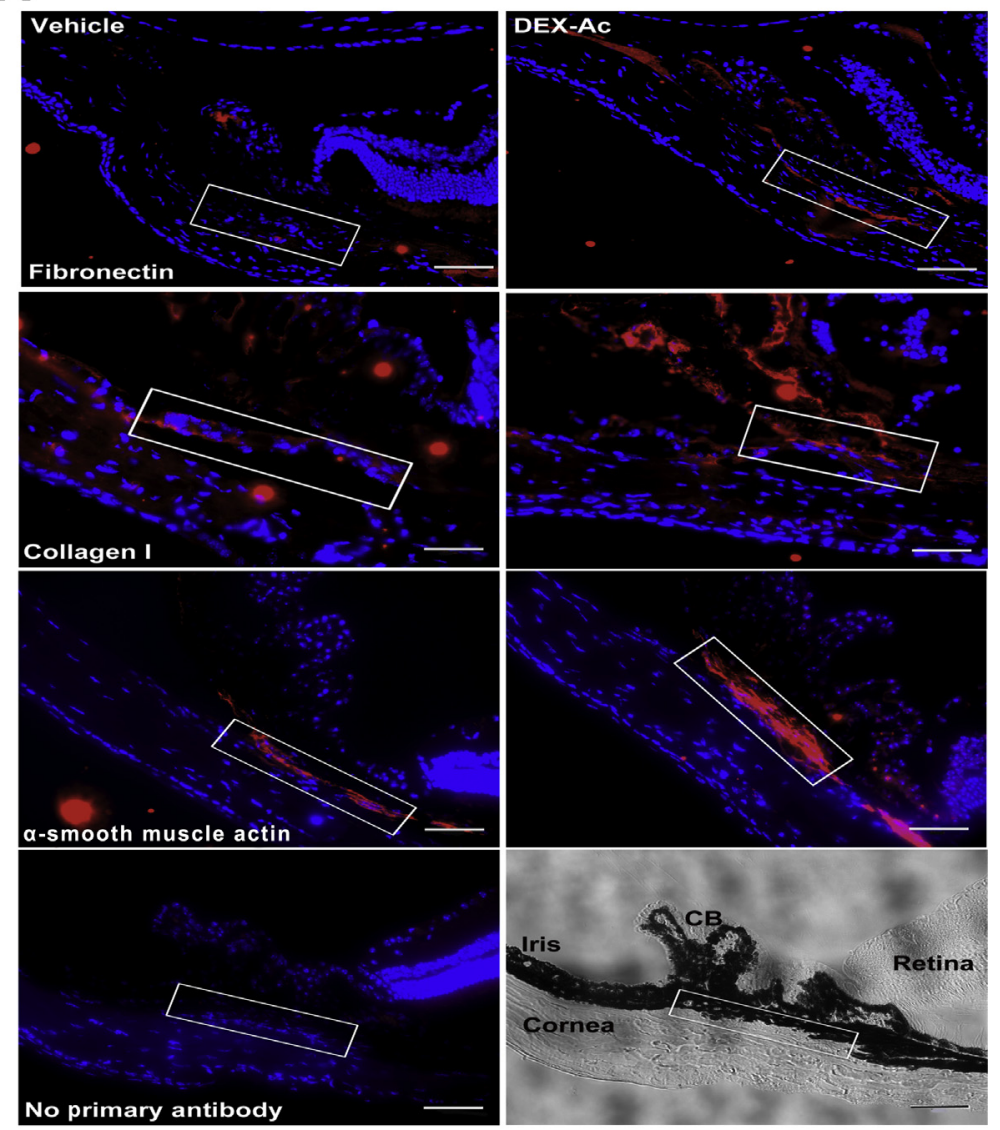

B
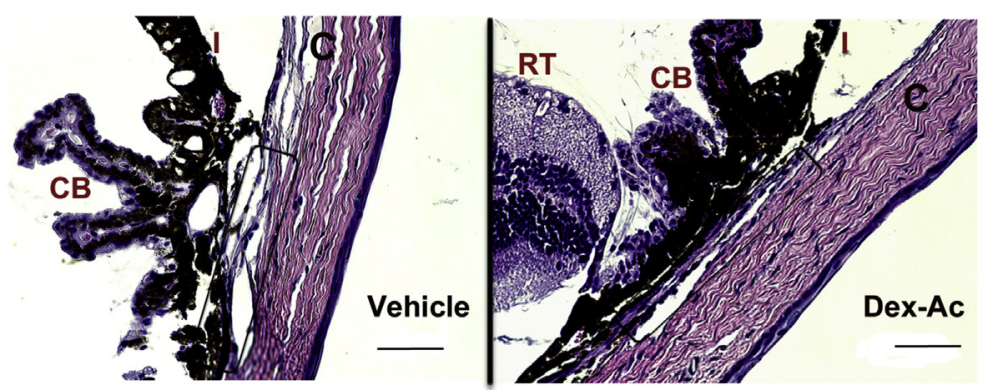

Figure 4 DEX-Ac treatment increases expression of fibronectin, collagen I, and $\alpha$-smooth muscle actin in the trabecular meshwork (TM) of mouse eyes. A: Immunohistochemical analysis showing increased expression of fibronectin (red), collagen I (red), and $\alpha$-smooth muscle actin (red) in DEX-Ac-treated mice (right column) compared to vehicle-treated mice (left column). DAPI staining (blue) counterstains cell nuclei. No primary antibody staining control (bottom left panel). Bright field image showing structural orientation of TM with respect to other ocular structures (bottom right panel). Boxed areas indicate TM. B: Hematoxylin and eosin staining reveals no apparent ocular abnormalities and a similar TM structural organization in DEX-AC- and vehicle-treated mice. Boxed areas indicate TM. $n=4$ (A, fibronectin and $\alpha$-smooth muscle actin DEX-Ac and vehicle); $n=5$ (A, collagen I DEX$A c$ and vehicle). Scale bars $=50 \mu \mathrm{m}$ (A and B). C, cornea; $\mathrm{CB}$, ciliary body; I, iris; RT, retina.
DEX-Ac treatment increases myocilin expression in the TM region by performing immunostaining of anterior segment tissues. Myocilin immunostaining was higher in the TM of DEX-Ac-treated mice (Figure 5A). Consistent with immunostaining analysis, Western blot analysis from anterior segment tissue lysates showed increased expression of fibronectin and myocilin in WT mice after DEX-Ac treatment (Figure 5B). However, in myocilin knockout $\left(\mathrm{Myoc}^{-l-}\right)$ mice, there was no expression of myocilin after DEX-Ac treatment, even though there was increased expression of fibronectin similar to that observed with WT DEX-Ac-treated mice (Figure 5B). Because it has not yet been determined whether DEX leads to IOP elevation in Myoc knockout mice, we injected DEX-Ac and compared IOP elevation in both WT and $\mathrm{Myoc}^{-1-}$ mice. The baseline
IOPs for both WT and $M y c^{-1-}$ were the same, and DEX-Ac-induced IOP elevation was rapid in both WT and Myoc $^{-1-}$ compared to vehicle-treated mice starting from 1 week of treatment. Conscious daytime IOP differences between DEX-Ac and vehicle groups in both WT and $\mathrm{Myoc}^{-1-}$ were sustained to approximately 4 to $5 \mathrm{mmHg}$ $(P=0.001)$ from week 1 throughout the course of treatment (Figure 5C). In WT mice, the absolute increase in IOP in DEX-Ac $(n=10)$ versus vehicle $(n=10)$ treated mice averaged $3.9 \pm 0.03 \mathrm{mmHg}$ at 1 week, $3.7 \pm 0.08 \mathrm{mmHg}$ at 2 weeks, $4.9 \pm 0.18 \mathrm{mmHg}$ at 3 weeks, and $3.6 \pm$ $0.02 \mathrm{mmHg}$ at 4 weeks (means \pm SEM). Similar IOP differences between DEX-Ac and vehicle were observed in $\mathrm{Myoc}^{-1-}$ mice. In $\mathrm{Myoc}^{-1-}$ mice, the absolute increase in IOP in DEX-Ac $(n=12)$ versus vehicle $(n=6)$ treated 

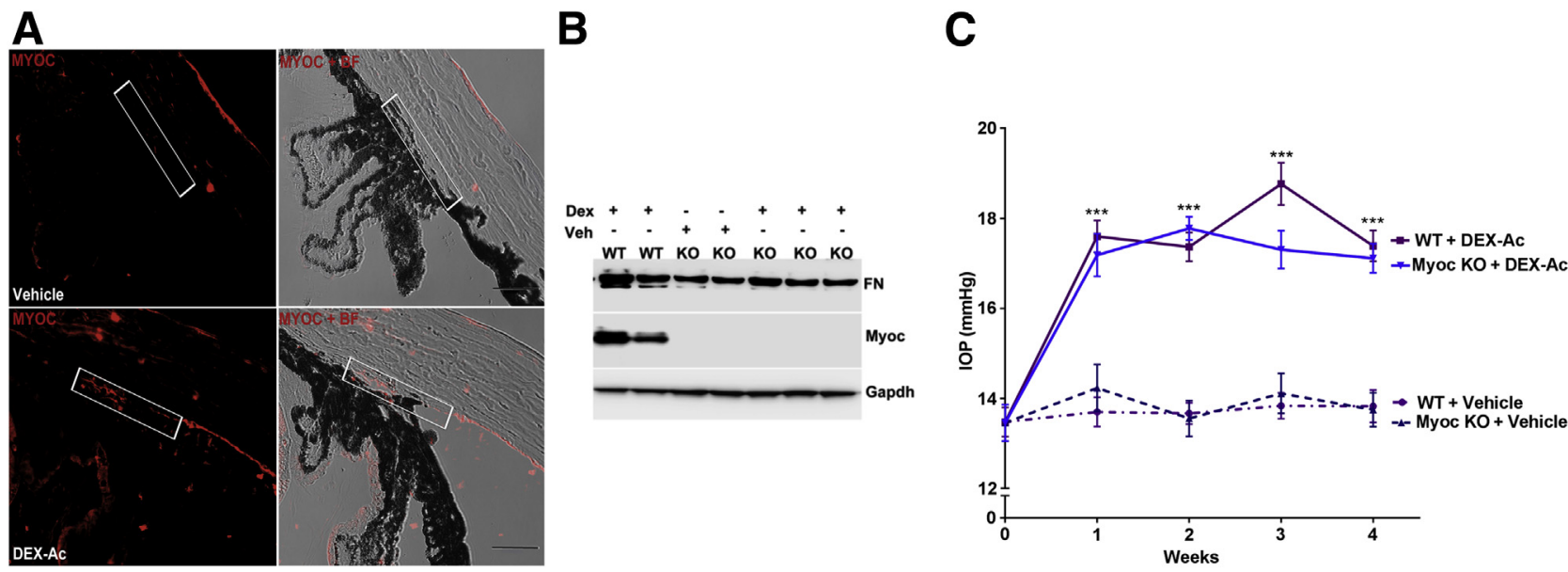

Figure 5 Intraocular pressure (IOP) elevation in wild-type (WT) and Myoc knockout (KO) mice after DEX-Ac treatment. A: Immunostaining for myocilin in the trabecular meshwork (TM; indicated by the boxed areas) of 4-week DEX-Ac- (bottom left panel) and vehicle- (top left panel) treated WT mice. Merged bright field (BF) fluorescence images (right column) provide detailed structural orientation. B: Representative Western blot image of fibronectin (FN) and myocilin (Myoc) in the anterior segment tissue lysates of DEX-Ac-treated WT mice and vehicle (Veh)- and DEX-Ac-treated $\mathrm{Myoc}^{-1-}$ mice. C: Weekly periocular conjunctival fornix (CF) injections of DEX-Ac significantly elevates IOP in both WT and Myoc ${ }^{-/-}$mice. Agematched WT and $\mathrm{MyOC}^{-/-}$mice were treated with vehicle or DEX-Ac, and conscious IOPs were measured weekly. DEX-Ac treatment of WT and $\mathrm{MyOC}^{-1-}$ mice show significant IOP elevation from 1 to 4 weeks compared to vehicle-treated littermates. Data are presented as means \pm SEM (C). $n=3$ (A, DEX-Ac- and vehicle-treated mice); $n=10$ (C, DEX-Ac-treated WT mice and vehicle-treated littermates); $n=12$ (C, DEX-Ac-treated Myoc $^{-/-}$mice). ${ }^{* *} P<0.001$, two-way analysis of variance. Scale bars $=50 \mu \mathrm{m}$. Gapdh, glyceraldehyde-3-phosphate dehydrogenase.

mice averaged $2.95 \pm 0.05 \mathrm{mmHg}$ at 1 week, $4.2 \pm 0.14$ $\mathrm{mmHg}$ at 2 weeks, $3.2 \pm 0.02 \mathrm{mmHg}$ at 3 weeks, and $3.3 \pm 0.05 \mathrm{mmHg}$ at 4 weeks (means \pm SEM). Multiple comparisons between groups using two-way analysis of variance showed that IOP was statistically significant between DEX-Ac and vehicle-treated mice in both WT and Myoc $^{-l-}$ mice (Supplemental Table S5). These results suggest that myocilin does not play a major role in DEX-induced OHT.

\section{Discussion}

GC-induced OHT is a serious adverse effect of prolonged GC therapy with patients. GC-induced IOP elevation, if left untreated, progresses to secondary open-angle glaucoma, involving glaucomatous optic neuropathy and permanent vision loss. However, the molecular mechanisms responsible for GC-induced ocular hypertension are not entirely clear. Animal models can provide better insights into pathogenesis of GC-induced OHT, and investigators have reported GC-OHT in eight different species besides human. ${ }^{4}$ In our study, we describe a mouse model of GC-OHT with a novel periocular CF delivery of DEX-Ac. This reproducible model is easy to run and captures many aspects of GC-induced OHT, including elevated IOP, reduction in the aqueous humor outflow facility, and reversibility of ocular hypertension after discontinuing GC treatment. This model also exhibits histological changes observed in the TM of GC-induced OHT eyes, including increased expression of fibronectin, collagen type I, $\alpha$-smooth muscle actin, and myocilin in the TM region. In addition, minimum systemic toxicity was associated with this local DEX-Ac treatment, as evident from unchanged body weight of mice treated with DEX-Ac compared to vehicle-treated mice. Furthermore, Myoc knockout mice developed similar DEX-induced ocular hypertension as WT mice, although myocilin expression increases in the TM of only WT mice in response to DEX treatment. ${ }^{26}$

Interestingly, the magnitude of DEX-OHT was greater at night ( $\Delta$ IOP 8 to $9 \mathrm{mmHg}$ in anesthetized mice) compared to daytime ( $\triangle \mathrm{IOP} 3$ to $4 \mathrm{mmHg}$ in conscious mice). Our findings agree with daytime/nighttime IOPs in POAG transgenic $\mathrm{MYOC}^{\mathrm{Y}}{ }^{437 \mathrm{H}}$ mice. ${ }^{37}$ This diurnal IOP variation in mice has been reported previously. ${ }^{50-52}$ Because mice are nocturnal animals, rates of aqueous humor formation are higher during active hours, which therefore cause higher nighttime IOPs, especially when the outflow facility is compromised. There are also diurnal IOP differences in other species, ${ }^{53-55}$ including humans. ${ }^{56,57}$ The magnitudes of the IOP fluxes are even greater in human eyes with glaucoma or ocular hypertension than in normal eyes, ${ }^{58}$ as seen in our model. Humans also have diurnal differences in rates of aqueous humor production, which are higher in the day compared to night. ${ }^{59}$ However, human IOPs are higher at night because of changing from upright to supine position, ${ }^{57}$ which does not occur in mice. Monitoring both daytime and nighttime IOPs may help us better understand and manage disease processes. Furthermore, the conventional outflow facility measured at 5 weeks of DEX-Ac treatment was significantly reduced in DEX-Ac-treated mice by $33 \%$ compared to vehicle-treated mice, and there was a correlation between elevated IOP and decreased conventional outflow facility. These results are consistent 
with previous studies of GC-induced OHT, including Whitlock et $\mathrm{al}^{43}$ and Overby et $\mathrm{al}^{45}$ using systemic DEX delivery, as well as Zode et $\mathrm{al}^{40}$ using topical ocular DEX treatment. Kumar et $\mathrm{al}^{44}$ used subconjunctival delivery of triamcinolone acetonide to show decreased conventional outflow facility, but this was not correlated with IOP elevation. We also were unable to get reproducible IOP elevation with subconjunctival DEX administration.

Several studies ${ }^{43,45}$ have reported a high dropout rate and reduction in body weight in response to systemic DEX treatment. In contrast, we found minimal to no systemic toxicity associated with DEX treatment, as measured by potential loss in body weight in our mouse model. In addition, our mouse model requires minimally invasive periocular CF injections on a weekly basis under mild anesthesia, which is effective and efficient, and minimizes animal distress compared to systemic DEX delivery. Systemic DEX delivery in mice used surgical implantation of minipumps into the backs of mice, ${ }^{4,45}$ whereas topical ocular DEX administration required administration of eye drops three times daily for multiple weeks by a trained technician. ${ }^{40}$ We tried formulating DEX and DEX-Ac, which are not soluble in aqueous formulations and require suspension formulations. Although DEX-21-phosphate is soluble in aqueous solutions, it did not provide prolonged delivery and did not reproducibly elevate IOP when administered by periocular CF injections. We found that the formulation of DEX-Ac and its consistency is important to get reproducible results. DEX-Ac will form larger precipitates and clumps when in suspension longer than 2 weeks. Therefore, it is essential to use freshly prepared formulations every 2 weeks.

Consistent with other previously reported studies $^{13,20,22,40,45}$ that show DEX-induced biochemical changes in the TM, we found similar biochemical changes in TM of our mouse model after DEX-Ac treatment. The expression of fibronectin, collagen I, myocilin, and $\alpha$-smooth muscle actin increased in the TM of DEXAc-treated mice compared to vehicle-treated mice. Thus, our mouse model appropriately mimics many aspects of GC-induced OHT, which is similar to humans and other species.

MYOC was first reported as a DEX-induced gene and protein in cultured human TM cells. ${ }^{24,26,27}$ MYOC was discovered as the first gene responsible for juvenile open-angle glaucoma and a subset of POAG. ${ }^{25,28,29}$ The current function of $M Y O C$ is unknown, but it has been suggested that $M Y O C$ might play a role in development of GC-induced OHT and secondary glaucoma. MYOC expression and OHT induction occur in response to GCs, and both follow similar time-course and dose-response curves. $^{26,60,61}$ Few studies have addressed the potential role of myocilin in GC-induced OHT. Both Shepard et $\mathrm{al}^{62}$ and Kirstein et $\mathrm{al}^{63}$ showed that myocilin induction by GCs was because of other transcription factors or remote glucocorticoid response elements and not by sequences in the proximal region of the myocilin gene promoter. Another study by Fingert et $\mathrm{al}^{64}$ compared steroid responders and control subjects for changes in myocilin gene sequences, and there was no correlation between myocilin gene variations and steroid response. However, there are no functional studies that demonstrate that the GC induction of myocilin is necessary for GC-induced OHT. Consistent with previous studies, we also observed increased myocilin expression in the TM of WT mice after DEX treatment. ${ }^{23,24}$ To address whether DEX-induced myocilin plays a role in IOP elevation, we compared the IOP responses to DEX-Ac treatment in WT and $\mathrm{Myoc}^{-1-}$ mice. IOP remained significantly elevated in both WT and $\mathrm{Myoc}^{-1-}$ DEX-Ac-treated mice compared to vehicle-treated WT and $\mathrm{Myoc}^{-1-}$ mice, indicating that myocilin is not involved in DEX-induced OHT.

In summary, our mouse model of DEX-induced OHT mimics many aspects of GC-induced OHT observed in humans, including IOP elevation, reduced conventional outflow facility, and biochemical changes in TM. The nighttime IOP was higher with ocular hypertensive eyes compared to normal eyes. With periocular CF injection of DEX-Ac, we did not find any obvious signs of systemic toxicity associated with DEX. IOP started returning to baseline when DEX-Ac treatment was stopped, suggesting that this model mimics many features of GC-OHT in human eyes, including the reversibility of ocular hypertension after discontinuation of GC therapy. Using this mouse model, we further demonstrate that loss of myocilin does not prevent GC-induced OHT. Mouse genetics and new genome editing tools will allow identification of the factors and pathways involved in the development of GC-OHT in this new model.

\section{Acknowledgments}

We thank Sandra Maansson and Sherri Harris for technical assistance; Iok-Hou Pang and Weiming Mao for helpful discussions in preparation of DEX formulations; and Motifolio Inc. (Sykesville, MD) for assistance in preparing Figure 1A.

\section{Supplemental Data}

Supplemental material for this article can be found at http://dx.doi.org/10.1016/j.ajpath.2016.12.003.

\section{References}

1. Ramamoorthy S, Cidlowski JA: Corticosteroids: mechanisms of action in health and disease. Rheum Dis Clin North Am 2016, 42: 15-31. vii

2. Overman RA, Yeh JY, Deal CL: Prevalence of oral glucocorticoid usage in the United States: a general population perspective. Arthritis Care Res (Hoboken) 2013, 65:294-298 
3. Fardet L, Petersen I, Nazareth I: Prevalence of long-term oral glucocorticoid prescriptions in the UK over the past 20 years. Rheumatology (Oxford) 2011, 50:1982-1990

4. Overby DR, Clark AF: Animal models of glucocorticoid-induced glaucoma. Exp Eye Res 2015, 141:15-22

5. Gaudana R, Ananthula HK, Parenky A, Mitra AK: Ocular drug delivery. AAPS J 2010, 12:348-360

6. Clark AF, Wordinger RJ: The role of steroids in outflow resistance. Exp Eye Res 2009, 88:752-759

7. Wordinger RJ, Clark AF: Effects of glucocorticoids on the trabecular meshwork: towards a better understanding of glaucoma. Prog Retin Eye Res 1999, 18:629-667

8. Kersey JP, Broadway DC: Corticosteroid-induced glaucoma: a review of the literature. Eye (Lond) 2006, 20:407-416

9. Armaly MF: Statistical attributes of the steroid hypertensive response in the clinically normal eye, I: the demonstration of three levels of response. Invest Ophthalmol 1965, 4:187-197

10. Armaly MF, Becker B: Intraocular pressure response to topical corticosteroids. Fed Proc 1965, 24:1274-1278

11. Stamer WD, Clark AF: The many faces of the trabecular meshwork cell. Exp Eye Res 2016. [Epub ahead of print] doi:10.1016/j.exer. 2016.07.009

12. Clark AF, Wilson K, McCartney MD, Miggans ST, Kunkle M, Howe W: Glucocorticoid-induced formation of cross-linked actin networks in cultured human trabecular meshwork cells. Invest Ophthalmol Vis Sci 1994, 35:281-294

13. Clark AF, Brotchie D, Read AT, Hellberg P, English-Wright S, Pang IH, Ethier CR, Grierson I: Dexamethasone alters F-actin architecture and promotes cross-linked actin network formation in human trabecular meshwork tissue. Cell Motil Cytoskeleton 2005, 60:83-95

14. Mao W, Liu Y, Mody A, Montecchi-Palmer M, Wordinger RJ, Clark AF: Characterization of a spontaneously immortalized bovine trabecular meshwork cell line. Exp Eye Res 2012, 105:53-59

15. O'Reilly S, Pollock N, Currie L, Paraoan L, Clark AF, Grierson I: Inducers of cross-linked actin networks in trabecular meshwork cells. Invest Ophthalmol Vis Sci 2011, 52:7316-7324

16. Wade NC, Grierson I, O'Reilly S, Hoare MJ, Cracknell KP, Paraoan LI, Brotchie D, Clark AF: Cross-linked actin networks (CLANs) in bovine trabecular meshwork cells. Exp Eye Res 2009, $89: 648-659$

17. Zhang X, Ognibene CM, Clark AF, Yorio T: Dexamethasone inhibition of trabecular meshwork cell phagocytosis and its modulation by glucocorticoid receptor beta. Exp Eye Res 2007, 84:275-284

18. Johnson DH, Bradley JMB, Acott TS: The effect of dexamethasone on glycosaminoglycans of human trabecular meshwork in perfusion organ culture. Invest Ophthalmol Vis Sci 1990, 31:2568-2571

19. Engelbrecht-Schnür S, Siegner A, Prehm P, Lütjen-Drecoll E: Dexamethasone treatment decreases hyaluronan-formation by primate trabecular meshwork cells in vitro. Exp Eye Res 1997, 64:539-543

20. Steely HT, Browder SL, Julian MB, Miggans ST, Wilson KL, Clark AF: The effects of dexamethasone on fibronectin expression in cultured human trabecular meshwork cells. Invest Ophthalmol Vis Sci 1992, 33:2242-2250

21. Dickerson JE Jr, Steely HT Jr, English-Wright SL, Clark AF: The effect of dexamethasone on integrin and laminin expression in cultured human trabecular meshwork cells. Exp Eye Res 1998, 66:731-738

22. Zhou L, Li Y, Yue BY: Glucocorticoid effects on extracellular matrix proteins and integrins in bovine trabecular meshwork cells in relation to glaucoma. Int J Mol Med 1998, 1:339-346

23. Yun AJ, Murphy CG, Polansky JR, Newsome DA, Alvarado JA: Proteins secreted by human trabecular cells: glucocorticoid and other effects. Invest Ophthalmol Vis Sci 1989, 30:2012-2022

24. Nguyen TD, Chen P, Huang WD, Chen H, Johnson D, Polansky JR: Gene structure and properties of TIGR, an olfactomedin-related glycoprotein cloned from glucocorticoid-induced trabecular meshwork cells. J Biol Chem 1998, 273:6341-6350
25. Stone EM, Fingert JH, Alward WLM, Nguyen TD, Polansky JR, Sunden SLF, Nishimura D, Clark AF, Nystuen A, Nichols BE, Mackey DA, Ritch R, Kalenak JW, Craven ER, Sheffield VC: Identification of a gene that causes primary open angle glaucoma. Science 1997, 275:668-670

26. Polansky JR, Fauss DJ, Chen P, Chen H, Lutjen-Drecoll E, Johnson D, Kurtz RM, Ma ZD, Bloom E, Nguyen TD: Cellular pharmacology and molecular biology of the trabecular meshwork inducible glucocorticoid response gene product. Ophthalmologica 1997, 211:126-139

27. Clark AF, Steely HT, Dickerson JE Jr, English-Wright S, Stropki K, McCartney MD, Jacobson N, Shepard AR, Clark JI, Matsushima H, Peskind ER, Leverenz JB, Wilkinson CW, Swiderski RE, Fingert JH, Sheffield VC, Stone EM: Glucocorticoid induction of the glaucoma gene MYOC in human and monkey trabecular meshwork cells and tissues. Invest Ophthalmol Vis Sci 2001, 42:1769-1780

28. Kubota R, Noda S, Wang Y, Minoshima S, Asakawa S, Kudoh J, Mashima Y, Oguchi Y, Shimizu N: A novel myosin-like protein (myocilin) expressed in the connecting cilium of the photoreceptor: molecular cloning, tissue expression, and chromosomal mapping. Genomics 1997, 41:360-369

29. Alward WL, Kwon YH, Khanna CL, Johnson AT, Hayreh SS, Zimmerman MB, Narkiewicz J, Andorf JL, Moore PA, Fingert JH, Sheffield VC, Stone EM: Variations in the myocilin gene in patients with open-angle glaucoma. Arch Ophthalmol 2002, 120:1189-1197

30. Fingert JH, Stone EM, Sheffield VC, Alward WL: Myocilin glaucoma. Surv Ophthalmol 2002, 47:547-561

31. Gould DB, Miceli-Libby L, Savinova OV, Torrado M, Tomarev SI, Smith RS, John SW: Genetically increasing Myoc expression supports a necessary pathologic role of abnormal proteins in glaucoma. Mol Cell Biol 2004, 24:9019-9025

32. Gould DB, Reedy M, Wilson LA, Smith RS, Johnson RL, John SW: Mutant myocilin nonsecretion in vivo is not sufficient to cause glaucoma. Mol Cell Biol 2006, 26:8427-8436

33. Kim BS, Savinova OV, Reedy MV, Martin J, Lun Y, Gan L, Smith RS, Tomarev SI, John SW, Johnson RL: Targeted disruption of the myocilin gene (Myoc) suggests that human glaucoma-causing mutations are gain of function. Mol Cell Biol 2001, 21:7707-7713

34. Zhou Y, Grinchuk O, Tomarev SI: Transgenic mice expressing the Tyr437His mutant of human myocilin protein develop glaucoma. Invest Ophthalmol Vis Sci 2008, 49:1932-1939

35. Shepard AR, Jacobson N, Millar JC, Pang IH, Steely HT, Searby CC, Sheffield VC, Stone EM, Clark AF: Glaucoma-causing myocilin mutants require the Peroxisomal targeting signal-1 receptor (PTS1R) to elevate intraocular pressure. Hum Mol Genet 2007, 16:609-617

36. Senatorov V, Malyukova I, Fariss R, Wawrousek EF, Swaminathan S, Sharan SK, Tomarev S: Expression of mutated mouse myocilin induces open-angle glaucoma in transgenic mice. J Neurosci 2006, 26:11903-11914

37. McDowell CM, Luan T, Zhang Z, Putliwala T, Wordinger RJ, Millar JC, John SW, Pang IH, Clark AF: Mutant human myocilin induces strain specific differences in ocular hypertension and optic nerve damage in mice. Exp Eye Res 2012, 100:65-72

38. Zode GS, Kuehn MH, Nishimura DY, Searby CC, Mohan K, Grozdanic SD, Bugge K, Anderson MG, Clark AF, Stone EM, Sheffield VC: Reduction of ER stress via a chemical chaperone prevents disease phenotypes in a mouse model of primary open angle glaucoma. J Clin Invest 2015, 125:3303

39. Jacobson N, Andrews M, Shepard AR, Nishimura D, Searby C, Fingert JH, Hageman G, Mullins R, Davidson BL, Kwon YH, Alward WL, Stone EM, Clark AF, Sheffield VC: Non-secretion of mutant proteins of the glaucoma gene myocilin in cultured trabecular meshwork cells and in aqueous humor. Hum Mol Genet 2001, 10: $117-125$

40. Zode GS, Sharma AB, Lin X, Searby CC, Bugge K, Kim GH, Clark AF, Sheffield VC: Ocular-specific ER stress reduction rescues 
glaucoma in murine glucocorticoid-induced glaucoma. J Clin Invest 2014, 124:1956-1965

41. Joe MK, Sohn S, Hur W, Moon Y, Choi YR, Kee C: Accumulation of mutant myocilins in ER leads to ER stress and potential cytotoxicity in human trabecular meshwork cells. Biochem Biophys Res Commun 2003, 312:592-600

42. Liu Y, Vollrath D: Reversal of mutant myocilin non-secretion and cell killing: implications for glaucoma. Hum Mol Genet 2004, 13: 1193-1204

43. Whitlock NA, McKnight B, Corcoran KN, Rodriguez LA, Rice DS: Increased intraocular pressure in mice treated with dexamethasone. Invest Ophthalmol Vis Sci 2010, 51:6496-6503

44. Kumar S, Shah S, Deutsch ER, Tang HM, Danias J: Triamcinolone acetonide decreases outflow facility in C57BL/6 mouse eyes. Invest Ophthalmol Vis Sci 2013, 54:1280-1287

45. Overby DR, Bertrand J, Tektas O-Y, Boussommier-Calleja A, Schicht M, Ethier CR, Woodward DF, Stamer WD, Lütjen-Drecoll E: Ultrastructural changes associated with dexamethasone-induced ocular hypertension in mice. Invest Ophthalmol Vis Sci 2014, 55:4922-4933

46. Wang WH, Millar JC, Pang IH, Wax MB, Clark AF: Noninvasive measurement of rodent intraocular pressure with a rebound tonometer. Invest Ophthalmol Vis Sci 2005, 46:4617-4621

47. Millar JC, Clark AF, Pang I-H: Assessment of aqueous humor dynamics in the mouse by a novel method of constant-flow infusion. Invest Ophthalmol Vis Sci 2011, 52:685-694

48. Millar JC, Phan TN, Pang I-H, Clark AF: Strain and age effects on aqueous humor dynamics in the mouse. Invest Ophthalmol Vis Sci 2015, 56:5764-5776

49. Kasetti RB, Phan TN, Millar JC, Zode GS: Expression of mutant myocilin induces abnormal intracellular accumulation of selected extracellular matrix proteins in the trabecular meshwork. Invest Ophthalmol Vis Sci 2016, 57:6058-6069

50. Ota T, Murata H, Sugimoto E, Aihara M, Araie M: Prostaglandin analogues and mouse intraocular pressure: effects of tafluprost, latanoprost, travoprost, and unoprostone, considering 24-hour variation. Invest Ophthalmol Vis Sci 2005, 46:2006-2011

51. Dalvin LA, Fautsch MP: Analysis of circadian rhythm gene expression with reference to diurnal pattern of intraocular pressure in mice. Invest Ophthalmol Vis Sci 2015, 56:2657-2663

52. Aihara M, Lindsey JD, Weinreb RN: Twenty-four-hour pattern of mouse intraocular pressure. Exp Eye Res 2003, 77:681-686
53. Moore CG, Johnson EC, Morrison JC: Circadian rhythm of intraocular pressure in the rat. Curr Eye Res 1996, 15:185-191

54. Bar-Ilan A: Diurnal and seasonal variations in intraocular pressure in the rabbit. Exp Eye Res 1984, 39:175-181

55. McLaren JW, Brubaker RF, FitzSimon JS: Continuous measurement of intraocular pressure in rabbits by telemetry. Invest Ophthalmol Vis Sci 1996, 37:966-975

56. Perlman JI, Delany CM, Sothern RB, Skolnick KA, Murray D, Jacobs RW, Shue JL, Kaplan E, Friedman NC, Nemchausky BA, Ryan MD, Kanabrocki EL: Relationships between 24h observations in intraocular pressure vs blood pressure, heart rate, nitric oxide and age in the Medical Chronobiology Aging Project. Clin Ter 2007, 158: $31-47$

57. Sit AJ, Liu JH: Pathophysiology of glaucoma and continuous measurements of intraocular pressure. Mol Cell Biomech 2009, 6:57-69

58. David R, Zangwill L, Briscoe D, Dagan M, Yagev R, Yassur Y: Diurnal intraocular pressure variations: an analysis of 690 diurnal curves. Br J Ophthalmol 1992, 76:280-283

59. Brubaker RF: Flow of aqueous humor in humans [the Friedenwald Lecture]. Invest Ophthalmol Vis Sci 1991, 32: 3145-3166

60. Polansky JR, Fauss DJ, Zimmerman CC: Regulation of TIGR/MYOC gene expression in human trabecular meshwork cells. Eye 2000, 14: 503-514

61. Polansky JR, Kurtz RM, Fauss DJ, Kim RY, Bloom E: In Vitro Correlates of Glucocorticoid Effects on Intraocular Pressure: Glaucoma Update IV. Berlin, Heidelberg, Springer Berlin Heidelberg, 1991. pp. 20-29

62. Shepard AR, Jacobson N, Fingert JH, Stone EM, Sheffield VC, Clark AF: Delayed secondary glucocorticoid responsiveness of MYOC in human trabecular meshwork cells. Invest Ophthalmol Vis Sci 2001, 42:3173-3181

63. Kirstein L, Cvekl A, Chauhan BK, Tamm ER: Regulation of human myocilin/TIGR gene transcription in trabecular meshwork cells and astrocytes: role of upstream stimulatory factor. Genes Cells 2000, 5: 661-676

64. Fingert JH, Clark AF, Craig JE, Alward WL, Snibson GR, McLaughlin M, Tuttle L, Mackey DA, Sheffield VC, Stone EM: Evaluation of the myocilin (MYOC) glaucoma gene in monkey and human steroid-induced ocular hypertension. Invest Ophthalmol Vis Sci 2001, 42:145-152 